\title{
SISTEMAS DE SAÚDE, COOPERAÇÃO HORIZONTAL E O PROGRAMA MAIS MÉDICOS NO BRASIL
}

\author{
Health systems, horizontal cooperation and the "Mais Médicos" program in Brazil \\ Sistemas de salud, cooperación horizontal y el programa más médicos en Brasil
}

\author{
Juliana Braga de Paula \\ Centro Universitário 7 de Setembro - Fortaleza (CE) - Brasil \\ Centro Universitário UniFanor/ Wyden - UniFanor/WIDEN - Fortaleza (CE) - Brasil \\ Instituto de Ensino e Pesquisa do Hospital Sírio Libanês - São Paulo (SP) - Brasil
}

\section{Marcia Faria Westphal}

Universidade de São Paulo - USP - São Paulo (SP) - Brasil

\section{RESUMO}

Objetivo: Analisar a Cooperação Brasil Cuba no Programa Mais Médicos (PMM) e seus efeitos para o trabalho médico. Métodos: Como parte do suplemento que discute os Sistemas Universais de Saúde, apresentar a experiência brasileira de provimento de médicos, o desenho da cooperação internacional e as implicações para um sistema de saúde em construção. Para analisar o programa, adota-se a abordagem do Ciclo de Políticas (Howlett e Ramesh ${ }^{(1)}$ e Bowe e Ball(2)) - entrevistas com atores chaves, análise documental e estudo de caso do PMM de duas cidades do Estado do Ceará. Resultados: Na dimensão macropolítica, as entrevistas mostram a prática e a educação médica voltadas para a atenção especializada, orientadas pelo mercado, com um uso exagerado de tecnologias de alta densidade, comparadas aos médicos cubanos. Os médicos cubanos trazem nova perspectiva para os profissionais de saúde na forma de construir vínculos com usuários e na maneira de lidar com a pobreza e a iniquidade. Conclusão: Na dimensão micropolítica, ambos, brasileiros e cubanos, beneficiam-se de estratégias de educação permanente e compartilhamento de estratégias no planejamento local.

Descritores: Saúde Pública; Política de Saúde; Sistemas de Saúde.

\section{ABSTRACT}

Objective: To analyze the Brazil-Cuba Cooperation in the More Doctors Program (Programa Mais Médicos - PMM) and its effects for the medical work. Methods: As part of the supplement that discusses the Universal Health Systems, to present the Brazilian experience in providing physicians, the design of the international cooperation and the implications for a health system under construction. For analysis of the program, the Policy Cycle approach (Howlett and Ramesh ${ }^{(1)}$ and Bowe and Ball(1)) key informant interviews, document analysis and case study on the PMM of two cities of the State of Ceará. Results: In the macropolitical dimension, the interviews show the medical practice and education focused on specialized, market-oriented care, with an exaggerated use of high-density technologies, compared to Cuban doctors. The Cuban doctors bring new perspectives to health professionals in how to build links with users and how to deal with poverty and inequity. Conclusion: In the micropolitical dimension, both Brazilians and Cubans benefit from strategies of continuing education and sharing of strategies in local planning.

Descriptors: Public Health; Health Policy; Health Systems.

\section{RESUMEN}

Objetivo: Analizar la Cooperación Brasil-Cuba para el Programa Más Médicos (PMM) y sus efectos en el trabajo médico. Métodos: Presentar la experiencia brasileña de proporcionar los médicos, el dibujo de la cooperación internacional y las implicaciones para un sistema de salud en construcción como parte del suplemento que discute los Sistemas Universales de Salud. Para analizar el programa se adoptó el abordaje del Ciclo de Políticas (Howlett y Ramesh ${ }^{(1)}$ y Bowe y Ball(2)) - entrevistas con actores claves, el análisis documental y el estudio de caso del PMM de dos ciudades del Estado de Ceará. Resultados: En la dimensión

Este artigo foi selecionado, corrigido e aprovado pela Comissão Científica do Fórum Internacional de Sistemas Universais de Saúde, seguindo suas normas e formatação. 
macro política, las entrevistas muestran la práctica y la educación médica dirigida para la atención especializada orientada por el mercado con el uso exagerado de las tecnologías de alta densidad comparándose con los médicos cubanos. Los médicos cubanos traen nueva perspectiva para los profesionales sanitarios en la forma de construir vínculos con los usuarios y en el modo de lidiar con la pobreza y la iniquidad. Conclusión: En la dimensión micro política, ambos, brasileños y cubanos se benefician de las estrategias de educación permanente y el compartimiento de estrategias para la planificación local.

Descriptores: Salud Pública; Política de Salud; Sistemas de Salud.

\section{INTRODUÇÃO}

Os sistemas de saúde em todo mundo passam por mudanças importantes, decorrentes, em parte, das transições (a) demográfica: população envelhecendo, queda da natalidade, aumento da expectativa de vida; (b) transição epidemiológica: aumento das doenças crônicas não transmissíveis e, ao mesmo tempo, manutenção de algumas doenças infectocontagiosas, ocasionando a dupla carga de doenças, associada ao aumento da morbidade e mortalidade por causas externas, (c) transição nutricional com mudança do padrão alimentar e consumo de produtos industrializados em ascensão, aumentando da obesidade, inclusive a infantil; (d) aumento da incorporação tecnológica de drogas e equipamentos, em alguns casos, iatrogênicos ${ }^{(3,4)}$.

Esse quadro de transição, aliado à globalização e ao ajuste fiscal, promovido pelas políticas econômicas dos anos 1990, ocasionaram uma crise de recursos humanos na saúde, materializada pela migração internacional de médicos e enfermeiros na busca de oportunidades e segurança ${ }^{(5)}$. Há escassez de profissionais médicos, má remuneração e má formação, ocasionando um braindrain dos países em desenvolvimento para os países ricos ${ }^{(6)}$. Em decorrência de baixos salários e falta de oportunidades, os países pobres têm perdido seus quadros profissionais com facilidade, gerando na comunidade internacional uma preocupação crescente com o Planejamento de Recursos Humanos em Saúde. A exemplo, a criação de um Pacto Global sobre o desenvolvimento de Recursos Humanos para a Saúde, pela Organização Mundial de Saúde em 2006(7).

O Brasil lançou em 2013 uma iniciativa de fortalecimento da atenção primária, através de atração e fixação de médicos em áreas remotas, com a implementação do Programa Mais Médicos (PMM ${ }^{(8)}$. Observados os critérios internacionais de recrutamento internacional e atração de médicos, a implantação do programa em território nacional foi considerada uma inovação. Os elementos fundamentais de uma inovação em um sistema de saúde são a sua complexidade, a intensidade de sua aplicação, a natureza imponderável da sua adoção e aplicação local. E é no sistema de adoção local, no momento da aplicação das várias teorias formuladas no desenho da política que uma iniciativa pode ou não se tornar uma inovação, a partir de sua relação com o contexto, com as transformações do objeto e com a receptividade, ou não, do desenho da inovação pelos atores que compõem o campo de prática. $O$ programa é lançado nesse período, mas já existia um desenho sendo montado, com visitas internacionais, missões diplomáticas a Cuba, Espanha e outros países com experiência de contratação/exportação de médicos e alguns fóruns internacionais de discussão sobre as estratégias de fixação de médicos em áreas remotas.

Em outubro de 2013, o Brasil promulgou finalmente a $\operatorname{Le}^{(8)}$ que definia uma série de medidas de fixação que envolviam: Provimento - contratação de médicos em caráter emergencial, brasileiros, intercambistas cubanos e intercambistas de outros países. Envolvia a mobilização de vários Ministérios, termo de cooperação travado com Cuba, validação do diploma de médico pelo próprio Ministério da Saúde; Estrutura - o mesmo Ministério se comprometia, conjuntamente com prefeituras e Estado a reformar as unidades que recebessem os médicos contratados pelo Programa; Formação - eixo que envolvia a interiorização e criação de cursos de medicina e de residência médica, e consequente abertura de novas faculdades pelo interior do país.

Embora a tentativa de fixar profissionais em áreas remotas não seja nova, a cooperação técnica entre países com a absorção de profissionais estrangeiros, intermediada por uma agencia das Nações Unidas, faz dessa política um campo de possibilidades de inovação no contexto de gestão do trabalho em saúde no Brasil? Entender qual a contribuição da cooperação Cuba Brasil para a política de gestão de trabalho em saúde no Brasil e no mundo é o foco central desta pesquisa que procura responder as seguintes questões: por que o Brasil precisou apostar em importação de médicos para lidar com as iniquidades na distribuição de médicos no país? Quais os efeitos da cooperação Cuba - Brasil na gestão do trabalho médico? Quais as estratégias de fomento à aprendizagem mútua entre cubanos e brasileiros a partir desse programa? O Programa Mais Médicos lança luz nas políticas de recursos humanos no Brasil? Quais as implicações para a carreira médica de medicina de família e comunidade no 
Brasil? Quais os problemas e as vantagens dessa cooperação? Assim, o objetivo do presente estudo foi analisar a Cooperação Brasil Cuba no Programa Mais Médicos (PMM) e seus efeitos para o trabalho médico.

\section{MÉTODOS}

Dentre os muitos referencias possíveis para analisar uma política, com a ampliação do escopo da revisão de literatura, o referencial do ciclo de políticas parecia ser o mais adequado para auxiliar no processo de compreensão como um todo. Inicialmente, apoiou-se em Howlett ${ }^{(1)}$, Ramesh ${ }^{(1)}$ e Kingdon ${ }^{(9)}$ para construir uma estratégia de investigação e análise das várias etapas de implementação, mas foi na abordagem de Stephen Ball ${ }^{(10)}$ do Ciclo de Políticas, com contextos que se entrelaçam que a pesquisa foi ancorada, por sua atualidade e capacidade de transitar entre o que se produziu no contexto da política até agora e o que se desdobra cotidianamente na prática dos serviços. Para Bowe e Ball(2), a política se divide em texto e discurso. Texto seria o que é produzido nos documentos oficiais, produtos inacabados que geram múltiplos níveis de tradução e interpretação. Discurso é o resultado das disputas de poder, pelo controle de recursos e do discurso em termos de vantagem e legitimidade. Reformulou-se a abordagem conceitual, a partir das contribuições anteriores, tomando por base encontros com Ball(10), que amplia o olhar sobre os atores e a interferência dos contextos na análise da política. Para efeito desse artigo, apresentarse-á parte dos resultados do estudo de caso que discorrem sobre os efeitos do programa nas cidades visitadas, o diálogo entre cubanos e brasileiros, a diferença da clínica, a estrutura para o atendimento e modelos de gestão.

Um dos focos do estudo de caso foi o acompanhamento do trabalho dos supervisores dos mais médicos, observação e entrevista dos médicos cubanos e não cubanos envolvidos no PMM e entrevista de gestores e outros profissionais envolvidos com o programa em duas cidades do interior do Estado do Ceará.

Parambu e Caucaia foram experiências distintas. Duas cidades no mesmo estado com características muito diversas.

Os dois municípios se complementam nos seus aspectos de diversidade e potencialidade, trazendo uma boa visão do escopo de prática. Ademais, os supervisores, também com formação e oriundos de instituições distintas, ampliam a visão de quem tenta explorar os vários aspectos do campo.

O primeiro aspecto observado na pesquisa foi a estrutura de trabalho, como os médicos cubanos trabalhavam e como acontecia a supervisão nesses espaços. As entrevistas eram direcionadas aos médicos cubanos e não cubanos intercambistas, supervisores, secretários de saúde e profissionais de outras áreas.

As supervisões foram acompanhadas e houve participação da pesquisadora de acordo com os objetivos da pesquisa e autorização prévia dos participantes. Às vezes, aconteciam estudos de caso, noutras discussões no campo teórico ou reflexões sobre a prática. Unidades foram visitadas e muitos dos profissionais presentes àquela visita contribuíam com informações sobre o campo.

Ao todo entrevistaram-se: 18 pessoas somente no contexto de prática, 14 cubanos, 2 supervisores, 1 gestora, 1 profissional de outra área. A supervisão de um dos municípios envolveu ainda 4 médicos não cubanos e uma médica cubana que não foram entrevistados, mas fizeram parte do compartilhamento de observações do campo, comentários sobre a prática e apresentação dos problemas e potencias das unidades envolvidas no programa das duas cidades. A pesquisa foi guiada por categorias prévias que foram refeitas ao longo do caminho. Os objetivos e a revisão de literatura foram os elementos norteadores das categorias em um primeiro momento, que foram transformadas pelos elementos que traziam mais sentido para a experiência do pesquisador em campo, da inter-relação com os entrevistados, as orientações em processo e o que a literatura foi fortalecendo nesse jogo de idas e vindas entre sujeitos, história e narrativa. (Figura 1).

A análise documental ocorreu em todo o processo da pesquisa: os primeiros documentos; a Lei №12.871/2013 que institui o PMM; os documentos institucionais, as avaliações dos pesquisadores que foram compartilhadas na pesquisa e os relatórios na plataforma da OPAS, serviram de base para a construção do roteiro de entrevistas e forneceram mais elementos para sua análise. Também esclareceram pontos importantes das questões que ficavam inconclusas ou colocaram mais questões a serem discutidas. Para efeito desse artigo, será concentrado nas categorias relacionadas à prática clínica e ao trabalho médico.

O presente estudo foi aprovado por Comitê de Ética em Pesquisa com Seres Humanos de acordo com Parecer $n^{\circ}$ 1.885.885. A pesquisa respeitou todos os procedimentos éticos, em conformidade com a norma do CONEP (Comissão Nacional de Ética em Pesquisa) e a Resolução 466/12 do Conselho Nacional de Saúde (CNS) do Ministério da Saúde ${ }^{(11)}$. Para o estudo de bancos de dados secundários foram obtidas as permissões das autoridades responsáveis. 


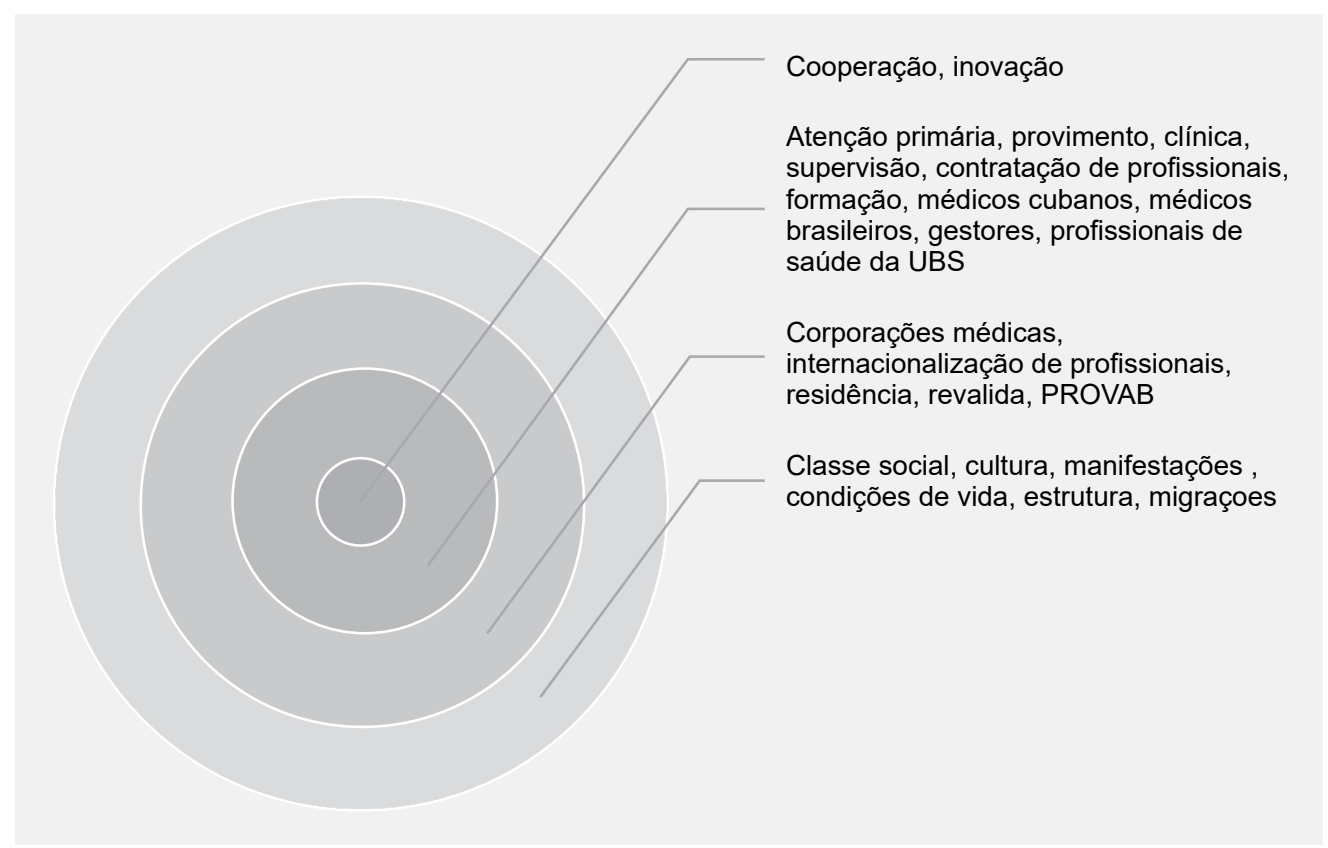

Fonte: Paula JB, 2017

Figura 1 - Categorias resultantes do campo de pesquisa.

\section{RESULTADOS E DISCUSSÃO}

As categorias mais importantes de observação do estudo estão relacionadas à infraestrutura do serviço, à construção de vínculos, à gestão, à clínica na APS, ao trabalho em equipe, à regulação e à clínica ampliada. Esses foram os itens fundamentais para análise dos efeitos desse programa sobre o trabalho médico no campo de prática.

\section{Infraestrutura do serviço}

Ao viajar para o campo, a primeira coisa que se observa são as dificuldades para o deslocamento para uma cidade do sertão. Em estrada de terra, aos solavancos, um ônibus levava 5 horas para chegar a Parambu. Em Caucaia, o problema de estrutura era outro. Eram unidades completamente sucateadas, onde portas viravam mesas e estruturas de inalação respiratória viravam ferrugem.

Os entrevistados afirmam que a presença ou a falta de estrutura interfere diretamente na capacidade de dar respostas aos problemas de saúde, relacionados com a falta de medicamentos e a falta de insumos para pequenos procedimentos:

"Eu acho que aqui no posto de saúde, houvesse um pouco mais de condição, por exemplo, na área de curativo. Se tivesse pinças, elementos para fazer suturas, elementos para fazer curativos, algodão, você poderia ajudar a contribuir a diminuir o efeito nos hospitais. Você poderia retirar pontos, fazer suturas, poderia fazer curativo. No caso da ginecologia, se usa muito tratamento via hormônio, tanto oral, como intramuscular. Isso está bem para uma idade determinada, que é entre término da adolescência, até uns 35 anos, quando uma mulher deve parir, não? Que se usa o anticoncepcional para evitar uma gravidez indesejada. Aqui se poderia por DIU e fazer prevenção ao câncer de colo de útero. Cuidaria mais das mulheres e não teria que encher tanto o hospital com esses pequenos procedimentos." (MC1)

\section{Gestão da atenção à saúde}

Há, ainda, problemas de gestão relacionados à má distribuição de insumos como medicamentos, ocasionando uma superlotação em determinadas unidades em detrimento de outras que ficam vazias porque não possuem os recursos adequados para finalizar o ciclo de atendimento de sua população:

"As medicações que têm lá elas são mal distribuídas, então talvez você tenha ido em um... eu não lembro que época que a gente foi, era mais no final do mês não é, não sei, mas talvez fosse uma época que tivesse medicação, mas por exemplo, anti-hipertensivo lá nos postos distantes, nos postos periféricos, eles chegam 
em quantidade inadequada, e aí você passa e não dá pra todo mundo. Aí a pessoa recebe a receita e tem que pegar no posto do centro. O quê que ela faz, ela nem consulta no posto dela, ela vai direto pro posto do centro, entende?" (S3)

$\mathrm{Na}$ visão de entrevistados da área médica, os médicos brasileiros sofrem com uma precarização do trabalho crônica e precisam fazer esse movimento entre várias prefeituras para poder se manter financeiramente, pois as prefeituras atrasam de 3 a 4 meses o salário do médico e a sobreposição de estações de trabalho permite que o médico seja pago em algum momento por uma dessas prefeituras. Uma das entrevistadas da corporação médica local aponta os seguintes elementos para reflexão:

"O que a gente tem hoje na nossa realidade são médicos que dão 72 horas de plantão, que se deslocam... a realidade hoje do médico do Ceará, o recém-formado é muito ruim. A gente viajou agora todo o sertão do Ceará, nós viajamos a região de Sobral, a região do Cariri e o que a gente encontrou foi médico com CRM de 15.000 a 17.000, ou seja, recém-egressos das faculdades que estão trabalhando na mesma semana simultaneamente em até 3 municípios. E como hoje a gente está tendo uma mudança do perfil nas faculdades de Medicina, $70 \%$ do egressos são mulheres. Me preocupa muito o fato dessas mulheres, por exemplo, nós encontramos moças em Iguatu que elas estavam vindo de 3 plantões seguidos." (C1)

Há uma visão de que os Cubanos, por estarem acostumados em situações de emergência e catástrofes, são mais propensos a trabalhar com estruturas deficientes. No entanto, nos relatos anteriores, uma das coisas mais criticadas pelos médicos cubanos foi exatamente a falta de estrutura para atuar nas unidades de saúde. Na visão de um supervisor do programa:

"Na realidade você conhece esse sistema, é um exército, talvez seja a segunda ou terceira renda do país, esse exército sanitário, e vários países do mundo lançam mão, inclusive países desenvolvidos, lançam mão desses médicos. E eles estão muito acostumados com catástrofes, por exemplo, então esses que estão comigo já estiveram em Angola, já estiveram em alguns lugares, Haiti, lugares de guerra ou lugares de terremoto ou lugares de situações muito adversas, então uma coisa que chama a atenção é que eles trabalham com o que têm. Isso é muito interessante." (S1)

Para alguns dos entrevistados, não há deficiência na clínica cubana, mas há problemas de comunicação, provavelmente relacionados ao idioma :

"Eu não vejo deficiências específicas nos médicos cubanos não. Pelo contrário, eu vejo eles com uma formação virada pra atenção primária sólida e quando eu vejo alguma dificuldade eu vejo mais dificuldade de comunicação." (S1)

Segundo esse mesmo supervisor, o cubano desenvolve com maior naturalidade atividades voltadas para organização do serviço e visitas domiciliares e o brasileiro teria uma clínica mais voltada para o modelo antigo, atendimento de demanda espontânea:

“(...) uma coisa interessante, você vê na atuação dos médicos cubanos, você vê um senso de organização, uma tentativa de organizar o serviço, uma tentativa de... as estratégias, por exemplo, a organização da demanda, visita domiciliar, isso é mais feito com naturalidade por eles. Os médicos brasileiros quando chegam eles casam bem com a gestão, porque a gestão não conhece a filosofia do "Saúde da Família", então médico recém-formado também não, então o quê que acontece, ele senta e atende, então a gestão usa muito médico brasileiro pra assistência direta, então o sujeito chega e atende." (S1)

\section{Construção de Vínculos}

Uma autoridade municipal afirma que o médico cubano passa mais tempo com o paciente:

"O médico cubano ele passa mais um tempo com o paciente, está certo? E às vezes, em determinados momentos no município nos deparamos com situações que eles não sabiam lidar e que humildemente eles vieram pra secretaria pra gente direcionar e ajudar a resolver. E a parte negativa que eu achei foi porque a resolutividade poderia ser mais (sic) na Atenção Básica e acabou sobrecarregando a nossa fila na Atenção Secundária, os nossos especialistas, mas também isso foi temporário." (G1) 
O sistema de regulação, a referência e contra referência no Brasil são falhos e isso se manifesta na fala dos cubanos:

“Você tem facilidade de fazer os encaminhamentos e receber retorno? Não, retorno não recebemos." (MC2)

Uma autoridade nacional afirma que o cubano trabalha melhor em equipe e se diferencia porque faz pequenos procedimentos na APS:

"Agora a impressão que me dá essa mudança é muito grande nas relações entre a equipe, ou seja, o que a gente está observando é que é médico um dos conhecimentos que são repassados é aquela capacidade de trabalhar melhor em equipe, o médico se preocupa mais de saúde, fala com a gente (com as pessoas), orienta, vai junto na visita domiciliar, com a enfermeira, ou seja, tem uma capacidade de se entrosar com a equipe e gerou efeitos positivo, mas não é bem recursos humanos, não é que ele se forma ou que ele passa conhecimentos mais do tipo técnico-científico. Por exemplo, médico cubano, qual é a diferença? Tem médico cubano que melhora a integralidade. Porque melhora a integralidade? Porque ele faz procedimento que $o$ médico brasileiro normalmente não faz na Atenção Primária: coloca DIU, pequenas cirurgias, aquelas lesões de pele de hipertensão de úlcera venosa." (A7)

Ao falar de sua equipe, a médica cubana ressalta a capacidade de construção de vínculos e de dedicação dos profissionais de saúde brasileiros:

"São pessoas que estão dedicadas à comunidade delas. Entregadas. E muito sacrificadas. Minha equipe, vou falar por mim. São pessoas qualificadas, são pessoas comprometidas com a comunidade, com o paciente, não tem horário para trabalhar. Não tem pressa, são pessoas que estão dedicadas ao paciente com muito amor, muita profissionalidade. Minhas agentes comunitárias, todas são concursadas. São todas pessoas com preparação, com conhecimento para fazer o que elas fazem aí. Comigo são muito boas, minha enfermeira muito boa também. Equipe muito boa." (MC6)

Na visão de uma autoridade de outro município, no entanto, o problema não está em ser cubano ou não, mas na possibilidade de vínculos construídos:

"Não, no atendimento domiciliar eu não percebo não, até porque os médicos do Parambu eles são parambuenses, então eles têm muitos vínculos com as famílias, pode até ser que eu possa perceber se vier um médico de fora e tudo, o que não é o caso no momento." (G1)

Ela continua afirmando que existem médicos e médicos independente da nacionalidade:

"Assim, nas visitas domiciliares eu tenho médico cubano que se destaca e tenho também médicos cubanos acomodados, como também brasileiro. A médica mesmo do centro de saúde ela é cubana e ela, as visitas mais próximas ela vai à pé fazer, está entendendo? Ela tem vontade de estar próxima das famílias. E a gente já tem outras Unidades que já existe uma acomodação de estarem realizando estas visitas." (G1)

\section{Clínica na APS}

Uma diferença marcante entre cubanos e brasileiros é que a clínica é que o primeiro é bem mais forte na avaliação diagnostica, na anamnese, na exploração dos fatores intervenientes e o outro é melhor nas tecnologias, principalmente os medicamentos, diz uma referência local do programa:

"Clínica... a diferença é a seguinte, é bem simples de explicar, eles usam a clínica, eles usam a propedêutica, a semiologia, a gente usa muito pouco aqui na formação. Lá, por questões ideológicas e por questões de limitações de recursos eles foram treinados muito na questão da propedêutica, da semiologia, então eles usam muito a clínica mesmo. A diferença básica é essa, as outras diferenças são inerentes às limitações que Cuba acaba tendo, então a gente vê, por exemplo, na questão da farmacologia, eles ficam mais limitados porque talvez eles não tenham à disposição o arsenal que a gente tem aqui, mas do ponto de vista clínico, do exame físico, da anamnese eu considero que eles são muito melhores que a gente." (R1)

Uma supervisora do programa se coloca na mesma direção, enfatizando o uso mais frequente da tecnologia pelos médicos brasileiros:

"Vejo. Eles são... eu acho que eles têm uma situação muito parecida com a gente aqui de escassez de recursos 
no sentido, assim, não que falte, mas que seja de uma escassez mesmo de tecnologia, que a Atenção Primária faz, que a Atenção Primária é você ter uma alta complexidade de problemas, mas usar uma baixa densidade tecnológica, então isso eles estão acostumados, então eles sabem lidar com isso, isso é o campo deles, então têm drogas que a gente deixou de usar aqui, mas que eles ainda usam e que é efetiva pra lá. Então o aparato clínico, eles examinam muito mais, eles utilizam muito o exame físico, diferente daqui. Aqui a gente passa exame, o exame complementar agora é o principal. Muitas vezes a gente não examina e passa o exame. Eles geralmente examinam, então assim, eles tentam resolver o máximo sem utilizar realmente..." (S2)

Essa supervisora se refere à diferença na clínica entre brasileiros e cubanos muito mais relacionada à escassez de médicos formados em medicina de família e comunidade, afirmando que nas regiões Sul e Sudeste onde a profissão é mais difundida, a clínica é mais resolutiva. Fala do perfil mais sanitarista do médico de família nordestino e da insegurança de fazer pequenos procedimentos cirúrgicos:

"Sim, eu acho que tem. Eu acho que tem, principalmente aqui no nordeste. Eu acho. A nossa formação de Medicina de Família no nordeste ela é muito sanitarista. Ela é muito de abordagem comunitária, da Saúde Coletiva, que eu acho importante, mas eu acho isso relega um pouco... eu acho que tem que ser meio a meio. A questão da técnica, então assim, a questão do procedimento, então fazer procedimentos, e isso é uma coisa que em Cuba se faz muito, eles fazem muitos procedimentos na clínica mesmo, então eles não têm medo de fazer. Então eles pedem material pra fazer. E mesmo o médico de família, principalmente o médico de família daqui, eu tenho observado daqui do nordeste, ele encaminha qualquer... sutura, drenagem de abcesso, tudo ele encaminha." (S2)

Segundo um tutor, há também diferença de protocolos clínicos que precisam ser adaptados pelos cubanos quando chegam no país, mas em relação à competência técnica ele não vê diferença:

"... há algumas diferenças em relação a alguns protocolos, da competência técnica. Alguns medicamentos que se usa em Cuba não se usa no Brasil e vice-versa, mas a medicina como um todo ela não tem tanta diferença; técnica, o que teve que ter inicialmente uma adaptação dos protocolos brasileiros aos medicamentos que são disponibilizados pelo SUS, com as dosagens dos antibióticos e determinados anti-hipertensivos, enfim, dosagem de medicamentos e o tipo de drogas, uma vez que houvesse essa padronização e tivesse $o$ conhecimento de quais seriam os medicamentos ou exames, a competência técnica ela se iguala, não tem nenhum problema." (T1)

Outra supervisora entrevistada fala da diferença da clínica cubana, afirmando que eles são realmente preparados para atuar na APS:

"Tem. Primeiro eu acho que, assim, os cubanos que vem eles são realmente preparados pra atuar em Atenção Primária, então esse olhar que talvez seja o meu olhar de formação é o olhar que eles têm. Então eles vêm geralmente já bem formados, com outros especialistas, já tiveram alguns que foram secretários de saúde, então eles têm um olhar direcionado pra Atenção Primária." (S2)

Pelos relatos, a clínica cubana e a estratégia de saúde da família brasileira, em sua concepção, se aproximam em relação a essa visão de ampliação de seu escopo e do reconhecimento dos determinantes sociais da saúde, do trabalho de equipe e do uso de instrumentos de desenvolvimento de uma intervenção que priorize as necessidades do paciente.

Em tese, as estratégias são similares, mas na prática cotidiana, por uma ausência de formação médica na área em larga escala, pela precarização do processo de trabalho, pela falta de planejamento de recursos humanos no país e a pouca oferta de profissionais disponíveis especialistas em medicina de família, a clínica brasileira transita entre a clínica oficial, degradada e tem lampejos de "clínica do sujeito"(12). A clínica cubana, pelas mesmas razões em contrário, ou seja, por ter formação adequada, por uma estabilidade trabalhista, por um planejamento e organização de serviço maior e por um modelo de sociedade que permite menos capturas para o mercado, teria mais aproximação com uma clínica ampliada. Há críticas à clínica cubana com relação ao uso da farmacologia e das tecnologias médicas.

Há, por outro lado, uma constatação de que a clínica brasileira é "tecnologia-dependente"(13), criando uma cultura de consumo de exames que se estende para o imaginário popular do que seria a "boa clínica". Há dimensões, no entanto, que ficam inconclusas nos relatos. 
Um estudo ${ }^{(14)}$ demonstra que os cubanos sabem fazer bem mais procedimentos: "Já com relação aos procedimentos que os médicos declararam saber fazer, o padrão observado quanto ao sexo, porte e distância do município foi semelhante àquele observado para os realizados. Entretanto, foi relatado saber fazer maior número de procedimentos por médicos cubanos e de outras nacionalidades, formados no exterior, que possuem título de especialistas, que tinham maior tempo de atuação na APS e que atuavam nas regiões Norte e Sudeste. Não houve diferença entre eles quanto ao tempo de graduação e ao de atuação na UBS" (p.2744).

Mas não houve mudança do escopo de prática, provavelmente devido à falta de estrutura das unidades ${ }^{(14): ~ " E n t r e ~}$ os motivos apresentados pelos médicos para não realizar, na UBS, os procedimentos e as atividades que relataram saber fazer, ressalta-se a falta de materiais e a infraestrutura inadequada, citada por $87,3 \%$ dos participantes. ( $p$. 2744)."

O mesmo foi observado nos relatos dessa presente pesquisa, mas o fato da ampliação não ocorrer, não quer dizer que não haja movimentação para a discussão dessas questões que foram reiteradas pelos cubanos diversas vezes nas entrevistas e nos encontros de supervisão. Os cubanos também têm legados das tecnologias de serviço, como o desenho do sistema, as redes de atenção à saúde, os sistemas de informação, as inovações tecnológicas (incluindo medicamentos) e o trabalho em equipe multiprofissional. Infelizmente, essa foi uma das lacunas desse Programa. Perdeu grande oportunidade de transformar a supervisão em uma janela de transformação das práticas e dos serviços de saúde no Brasil se tivesse envolvido supervisores não médicos e profissionais da equipe nos espaços de encontro. Pelas frestas, pelas dobras das intervenções clínicas, os profissionais não médicos foram afetados por esses encontros. Mas poderia ter saído do escopo tímido da clínica oficial e poderia ter adentrado pela clínica do sujeito.

Ampliando o espectro de articulação, possibilitando uma real intervenção sobre a clínica de atenção primária desse país. Afinal, formação e invenção guardam estreita relação uma com a outra e é nesses espaços de formação que a gente se transforma e outro sujeito emerge ${ }^{(15): ~ " O ~ p r o c e s s o ~ h i s t o ́ r i c o ~ d a ~ h o m i n i z a c ̧ a ̃ o ~ m o s t r a ~ q u e ~ a s ~ c u l t u r a s ~}$ e as sociedades tanto são transmitidas de uma geração para outra quanto, a todo momento, são reinventadas por processos educativos-formativos. Nesses termos, formação e invenção parecem guardar estreitas relações, a ponto de não podermos pensar os processos que lhes dão substancialidade como dissociados uns dos outros. Em suma, tudo se passa como se, de alguma maneira e em alguma medida, a formação envolvesse a invenção e vice-versa. (p.40)."

As ações de governo sozinhas, sem uma sociedade preparada para as transformações desejadas, não são sustentáveis. Isso leva a questionar ${ }^{(16)}$ se políticas de governo, mesmo institucionalizadas como políticas de Estado são sustentáveis. Pode-se, talvez, inferir que políticas públicas não são mais que disparadores, molas propulsoras que podem ou não ser recebidas pela sociedade, podem ou não ter efeitos permanentes na conjuntura social, dependendo dos atores envolvidos e do tempo que a política tem para ser compreendida e incorporada.

O PMM sobreviveu porque algo se instaurou nos cenários remotos, como o sertão, e atingiu atores que não estavam nos fluxos de poder. Não se sabe ainda o tamanho dos afetos, mas a partir deles e, no momento, só a partir deles, será visto o que resultou dessa movimentação política e social do Mais Médicos.

\section{CONSIDERAÇÕES FINAIS}

Como um estudo qualitativo, não há uma preocupação com o esgotamento das questões ou com a generalização dos fatos aqui observados ao longo dessa narrativa. O estudo mostra que a cultura, as relações de classe e a formação em atenção primária dos médicos cubanos diferenciam a clínica cubana da clínica brasileira. Por outro lado, a estrutura dos serviços, o modelo de atenção à saúde e de gestão não permitem que a clínica brasileira se desenvolva da forma que poderia.

O sistema de saúde brasileiro é tecnologia dependente e vem, ao longo dos anos, trazendo implicações para a clínica médica. $O$ trabalho médico no Brasil se beneficiou da cooperação com os cubanos a partir do momento que coloca em xeque a clínica degradada no país, que recebe formação permanente a partir de supervisores, que dá visibilidade a categoria de medicina de família e comunidade, até então pouco conhecida pela população. Mais estudos hão de ser feitos, no entanto, para explorar as várias dimensões dessa cooperação, suas possibilidades e problemas.

Manuscrito baseado na tese de doutorado: Análise do Ciclo de Políticas do Programa Mais Médicos no Brasil: Cooperação Cuba Brasil e seus efeitos para o trabalho médico. Defendida em dezembro de 2017. Programa de Saúde Global e Sustentabilidade, Universidade de São Paulo. 226fl. 


\section{REFERÊNCIAS}

1. Howlett M, Ramesh M. Policy Science and Policy Cicles. In: Howlett M, Ramesh M. Studying public policy: policy cicles and subsystems. Oxford: Oxford University Press; 2003. p. 2-19.

2. Bowe R, Ball SJ, Gold A. Reforming education and changing schools: case studies in policy sociology. London: Routledge; 1992.

3. Buss PM, Pellegrini A Filho. A saúde e seus determinantes sociais. Physis [Internet]. 2007 [acesso em 2017 Set 11];17(1):77-93. Disponível em: http://www.scielo.br/scielo.php?script=sci_arttext\&pid=S010373312007000100 006\&lng=en\&nrm=iso.

4. Temporão JG. Para onde vai o SUS?. In: Brasil. Conselho Nacional de Secretários de Saúde. CONASS Debate: caminhos da saúde no Brasil. Brasília: CONASS; 2014.

5. Dal Poz MR. A crise da força de trabalho em saúde. Cad Saúde Pública. 2013;29(10):1924-6.

6. Buss PM, Ferreira JR. Ensaio crítico sobre a cooperação internacional em saúde. Reciis. 2010;4(1):95-105.

7. World Health Organization. A universal truth: no health without workforce [Internet]. 2014 [acesso em 2015 Abr 22]. Disponível em: http://www.who.int/workforcealliance/knowledge/resources/hrhreport_summary_En_web. pdf.

8. Brasil. Lei n. 12.871, de 22 de outubro de 2013. Institui o Programa Mais Médicos, altera a lei $n^{\circ} 8.745$ de 9 de dezembro de 1993 e n. 6.932 de 7 de julho de 1981, e dá outras providências. Diário Oficial da República Federativa do Brasil, Brasília. 2013.

9. Kingdon JW. Agendas, Alternatives and Public Policies. 2a ed. Boston: Longman; 2011.

10. Ball SJ. Politics and Policy-making in Education: explorations in policy sociology. London: Routledge; 1990.

11. Brasil. Ministério da Saúde. Resolução CNS n. 466, de 12 de dezembro de 2012, nos termos do Decreto de Delegação de Competência de 12 de novembro de 1991. Diário Oficial da República Federativa do Brasil, Brasília. 2012.

12. Campos GWS. A clínica do sujeito: por uma clínica reformulada e ampliada. In: Campos GWS, organizador. Saúde Paidéia. São Paulo: Hucitec; 2003. p. 51-67.

13. Tesser CD. Medicalização social (II): limites biomédicos e propostas para a clínica na atenção básica. Interface [Internet]. 2006. [acesso em 2018 Set 07];10(20):347-62. Available from: http://www.scielo.br/scielo.php?script=sci_ arttext\&pid=S1414-32832006000200006\&lng=en

14. Nicolau Girardi S, Leite Carvalho C, Pierantoni CR, de Oliveira Costa J, de Sousa van Stralen AC, Viana Lauar T; et al. Avaliação do escopo de prática de médicos participantes do Programa Mais Médicos e fatores associados. Ciênc Saúde Colet. 2016;21(9):2739-48.

15. Costa SSG. Revisitando três proposições sobre formação e invenção. In: Rocha T. Graduações em dança no Brasil. O que será que será? Seminário de Dança. 9a ed. Joinville: Nova Letra; 2016.

16. Correia MOG. Por uma crítica imanente sobre os limites das políticas públicas de direitos sociais e o Estado na produção do bem comum no modo de produção capitalista. Saude soc. [Internet]. 2015. [acesso em 2018 Ago 02]; 24(Suppl 1):55-65. Disponível em: http://www.scielo.br/scielo.php?script=sci_arttext\&pid=S0104$12902015000500055 \&$ Ing $=$ en

\section{Endereço para correspondência:}

Juliana Braga de Paula

Centro Universitário 7 de Setembro

Av. Almirante Maximiniano da Fonseca, 1395

Bairro: Engenheiro Luciano Cavalcante

CEP: 60811-020 - Fortaleza - CE - Brasil

E-mail: julianadepaula5@gmail.com 